\title{
USO DE ESPÉCIES EXÓTICAS EM PRAÇAS PÚBLICAS DE SALINAS- MG E O PARALELISMO CLIMÁTICO EM QUESTÃO
}

\author{
USE OF EXOTIC SPECIES IN PUBLIC SQUARES OF SALINAS-MG AND CLIMATE \\ PARALLELISM IN QUESTION \\ Leonardo Luiz Silveira da Silva', Marcos Vinícius Miranda Aguilar ${ }^{2}$, \\ Larissa Santos Rocha da Silva ${ }^{1}$, Saulo Antônio de Castro \\ ${ }^{1}$ Instituto Federal do Norte de Minas Gerais, Salinas, MG, Brasil - leonardo.silveira@ifnmg.edu.br \\ lariflorestal@hotmail.com \& saulinhodecastro87@gmail.com \\ ${ }^{2}$ Universidade Federal de Santa Maria, Santa Maria, Rio Grande do Sul, Brasil - \\ aguilarmarcos2009@hotmail.com
}

\section{RESUMO}

O presente estudo objetivou realizar um inventário da flora de todas as praças públicas da cidade de Salinas-MG, e a partir dele, analisar o paralelismo climático entre o município e as regiões endêmicas das espécies inventariadas. Foram inventariadas todas as espécies arbóreas vivas que possuíam circunferência à altura do peito (CAP) maior ou igual a $10 \mathrm{~cm}$, conforme determina a Resolução Conjunta IEF/SEMAD № 1905 de 12/08/2013. Em relação à classificação quanto à origem, considerou-se como nativas, as árvores originadas do Brasil, e exóticas as árvores oriundas de outro país. Para a comparação climática, foi utilizada a classificação climática de Köppen-Geiger. Foram encontradas nas praças avaliadas 567 indivíduos arbóreos, sendo 340 de origem nativa e 200 exóticas. As espécies exóticas encontradas nas praças públicas analisadas apresentam-se coerentes com o paralelismo climático entre sua região de origem e o município estudado. Todavia, destacamos que estas não devem substituir as espécies nativas, uma vez que estas contribuem para manutenção da biodiversidade local.

PALAVRAS-CHAVE: Arborização urbana, Clima, Endêmico.

\begin{abstract}
The present study aimed to carry out an inventory of the flora of all public squares in the city of Salinas-MG, and from there, to analyze the scalistic parallelism between the municipality and the endemic regions of the inventoried species. All live tree species that had a circumference at breast height (CAP) greater than or equal to $10 \mathrm{~cm}$ were invented, as determined by Joint Resolution IEF / SEMAD No. 1905, of 12/08/2013. In relation to the classification as to the origin, consider as native, as trees originated in Brazil, and exotic as trees originating from another country. For climate comparison, the Köppen-Geiger climate classification was used. 567 trees were found in the evaluated squares, 340 of which were of native origin and 200 were exotic. The exotic species found in the public squares analyzed are consistent with the scalable parallelism between their region of origin and the municipality studied. However, we emphasize that they should not replace as native species, since they contribute to the maintenance of local biodiversity.
\end{abstract}

KEYWORDS: Urban arborization, Climate, Endemic. 


\section{INTRODUÇÃO}

As alterações provocadas pelo processo de urbanização resultaram em vários impactos negativos sob ponto de vista ambiental. Dessa forma, a expansão desordenada das cidades gerou uma série de alterações no meio natural como; a supressão da vegetação nativa, poluição ambiental, impermeabilização do solo pela pavimentação e edificações, dentre outros, comprometendo assim, a qualidade de vida das pessoas (SOUSA et al., 2019). Na tentativa de minimizar estes impactos, despontam-se algumas medidas que proporcionam melhor bem-estar para a população, dentre as quais se destacam os planejamentos bem sucedidos para a arborização urbana, em virtude dos diversos benefícios que as áreas verdes podem nos oferecer (CHAVES et al., 2019).

Todo tipo de vegetação presente em parques, praças, canteiros, jardins, avenidas e que tenha a finalidade de gerar benefícios ao ambiente e ao homem, podem ser considerados áreas verdes (SILVA et al., 2019). Estas áreas atuam como mitigadoras do fenômeno da ilha de calor, além de proporcionar diversas outras vantagens e benefícios ao ambiente. Dentre essas vantagens, Martini et al. (2018) afirma que a arborização possui papel relevante para manutenção das funções biológicoclimáticas, sendo um componente de extrema importância nas cidades, visto que as árvores fornecem sombra, absorve parte dos raios solares, reduz a temperatura e a evapotranspiração, influencia na retenção da umidade do solo e do ar, além de tornar a paisagem urbana aprazível. Silva et al. (2019) relata que a vegetação utilizada na arborização urbana desempenha algumas funções importantes que podem resultar em significativas melhorias ao meio urbano, bem como proteção contra ventos, abrigo para a fauna, além de afetar diretamente a interação entre a população e a percepção de bem-estar. Guilherme et al. (2018) alegam que a arborização também contribui para o estabelecimento de espaços de recreação, valorização histórico-cultural das cidades, sendo útil na prevenção de movimentos de massa e ainda pode ser aproveitada pela medicina popular.

Apesar das inúmeras vantagens proporcionadas pela presença de árvores em ambientes urbanos, a arborização urbana também merece uma atenção especial pelos problemas que podem acarretar, em função da falta de planejamento. Santos et al. (2015) ressalta que é necessário possuir bastante cautela na elaboração de projetos de arborização urbana, visto que o plantio de árvores realizado de forma inadequada à estrutura urbana pode causar conflitos com encanamentos, fiação elétrica, calhas, muros, calçamentos, e postes de iluminação. Desse modo, o cultivo de espécies florestais em uma determinada localidade deve possuir a finalidade de ornamentação harmonicamente ligada às intenções de promoção da melhoria microclimática, alicerceada em critérios técnico-científicos (CHAVES et al., 2019).

Considerando estes aspectos, a análise qualitativa da arborização urbana desempenha um papel indispensável para o planejamento das áreas verdes, visto que permite analisar a vegetação com base nos aspectos fitossanitários, florísticos, condições do plantio e manejo das árvores, sendo possível prever o aparecimento de desequilíbrio ambiental e prognosticar soluções apropriadas às características dos locais avaliados (SANTOS et al., 2015)

A escolha das espécies implantadas em um plano de arborização urbana passa pela avaliação dos atributos dos vegetais usados (SILVA et al., 2019). Assim, a análise da vegetação nativa forma um dos principais instrumentos para implantação de espécies aptas à esses locais, levando em consideração as condições climáticas e o local de origem das mesmas, não podendo, desta forma, meramente importar soluções de outros locais, sobretudo de regiões fitogeográficas diferentes (PINHEIRO \& SOUZA, 2017).

Entre os problemas mais comuns observados na arborização urbana destacam-se os problemas fitossanitários e uso de plantas exóticas. A inserção de espécies exóticas na arborização podem causar sérios impactos quando as escolhas, e as plantações são realizadas de maneira inadequada. Dessa forma, nota-se que na maioria dos casos, as plantas são selecionadas levando em consideração apenas os traços estéticos, sem considerar características importantes, como; a forma da copa, velocidade de crescimento e o local de origem (COSTA et al., 2017).

A exposição das plantas às condições adversas exige uma constante adequação, tornando as mesmas vulneráveis ao ataque de pragas e doenças. $O$ subdesenvolvimento das espécies também pode ser explicado pelas diferenças climatológicas básicas entre o seu local de endemismo e o local de implantação, que podem, por exemplo, submeter às espécies a regimes pluviométricos ou médias térmicas, que não condizem com suas necessidades (CECCHETTO et al., 2014).

As espécies exóticas além de não se comportarem da 
mesma maneira que no seu ambiente natural, ainda podem causar danos ao ambiente. Dentre estes, pode-se citar a perda da biodiversidade e alteração fisionômica da paisagem (SOUSA et al., 2017). Em contrapartida, a utilização de espécies nativas apresentam vantagens em relação às exóticas, podendo citar como exemplo, uma maior possibilidade de desenvolvimento e melhor adaptação ao clima e solo (PINHEIRO \& SOUZA, 2017). Dessa forma, a análise das praças públicas exige o conhecimento sobre a ecologia, botânica, as variações climáticas regionais e os estilos arquitetônicos.

Diante do exposto, o objetivo deste estudo consiste em realizar um inventário da flora de todas as praças públicas da cidade de Salinas-MG, e a partir dele, analisar o paralelismo climático entre o município e as regiões endêmicas das espécies inventariadas.

\section{MATERIAL E MÉTODOS}

\section{Classificação da área de estudo}

O estudo foi realizado em 24 praças públicas localizadas no município de Salinas-MG. O município localiza-se na mesorregião do Norte de Minas Gerais, nas coordenadas $16^{\circ} 10^{\prime} 19^{\prime \prime}$ de latitude Sul e $42^{\circ} 17^{\prime} 30^{\prime \prime}$ de longitude Oeste e possui seu sítio urbano encravado a 471 metros de altitude (Figura 1) (TOLEDO et al., 2009; MENEZES et al., 2019). Apresenta condições climáticas caracterizadas por longo período de estiagem, temperaturas médias elevadas e alta incidência da radiação solar. Além disso, mais da metade do seu total pluviométrico anual está concentrado em três meses: novembro, dezembro e janeiro. Apesar de claramente ser tipificado como clima tropical, a partir da presença de duas estações pluviométricas e com amplitude térmica anual próxima a $5 \mathrm{C}$, suas características climatológicas fazem com que classificações climáticas menos generalistas e mais apuradas apresentem-se conflitantes.

o longo período de estiagem do município contrasta com um total pluviométrico de $877 \mathrm{~mm}$ (Instituto Nacional de Meteorologia - INMET, 2018). Apesar da quantidade de chuva estar abaixo do que se observa em muitas outras áreas de domínio tropical, o volume surpreende devido ao rigor da estiagem exibida na maior parte do ano. Uma forte concentração pluviométrica em poucos meses acentua suas particularidades climatológicas, levando analistas a interpretarem de forma equivocada o arranjo climático local. Tais características contribuem, inclusive, para rápidas e grosseiras mudanças paisagísticas que estão, por sua vez, diretamente associadas à chegada da estação chuvosa.

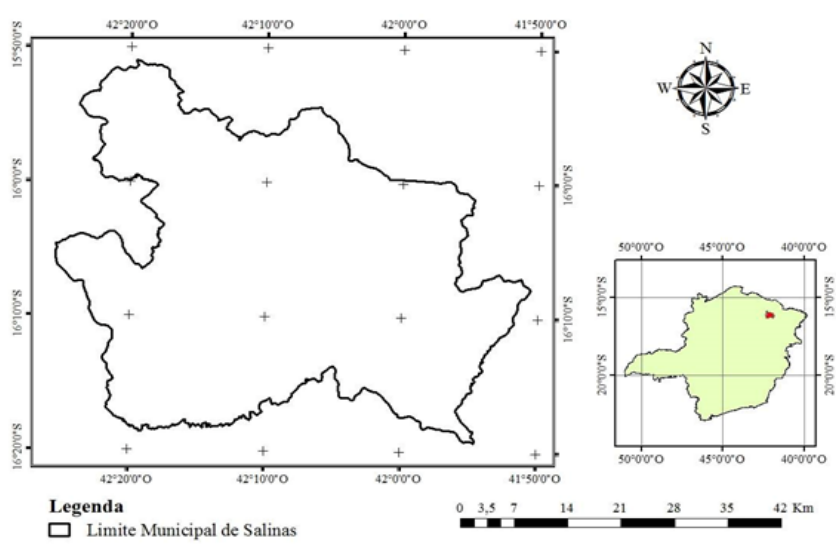

Figura 1. Localização do município de Salinas - MG.

Como exemplo, temos o fato de o município ter o seu clima não raramente classificado como BSh na classificação Köppen-Geiger, fato motivado provavelmente pelo longo período de estiagem. Contudo, o volume pluviométrico concentrado que supera os 800 $\mathrm{mm}$ anuais em média indica que esta classificação não é razoável, apesar dos limiares da classificação não estarem tão distantes. Já que a média de temperatura mais baixa, conforme a classe climática BSh foi observada no mês de junho, no patamar de $19^{\circ} \mathrm{C}$, e a maior média mensal no mês de janeiro, com a temperatura de $25,5^{\circ} \mathrm{C}$. As médias das temperaturas entre verão e inverno, estão entre $25,3^{\circ} \mathrm{C}$ e $22,8^{\circ} \mathrm{C}$, respectivamente. Observou-se que a distribuição da precipitação nessa classe climática é irregular e concentrou-se nos meses de novembro, dezembro e janeiro, possuindo uma média de $146 \mathrm{~mm}$ mensal, que corresponde cerca de $58 \%$ da média pluviométrica total anual de $755 \mathrm{~mm}$ (SÁ JUNIOR et al., 2012).

Além da classificação BSh que ocorre para o município de Salinas (MG), simultaneamente ocorre também a classificação Aw (SÁ JúNIOR et al., 2012). Nesta, o mês mais frio tem temperatura média superior a $18^{\circ} \mathrm{C}$, sendo que a precipitação anual é maior do que a evapotranspiração anual. Por carregar a letra " $w$ ", a tipologia informa que a estação seca é o inverno e que as chuvas concentram-se no verão (AYOADE, 2003). Existe ainda, a possibilidade de classificação do município como As: muitas vezes generalizado como Aw, a tipologia As destaca a estação chuvosa mais curta, inferior a 5 meses do ano. Contudo, o seu volume pluviométrico impede que a classificação leve à tipologia BSh.

O município de Salinas (MG) tem como população 
estimada 41.527 habitantes (Instituto Brasileiro de Geografia e Estatística - IBGE, 2019). É notório um processo de expansão de loteamentos em sua porção periférica, sendo este um momento ideal para discutir a forma de propor a arborização. Sabe-se que, externamente aos espaços verdes do município, a arborização é mal empregada, fazendo com que os momentos de sol a pino exponham os transeuntes à condição ambiental pouco salutar.

Observou-se também, na área urbana de Salinas (MG), diversos problemas associados à má implementação da arborização urbana. Desta forma, este artigo objetiva estabelecer uma avaliação comparada do clima de Salinas (MG) com àqueles que predominam nas áreas de endemismo das espécies exóticas plantadas nas áreas verdes da cidade, a fim de verificar se o poder público tem se atentado a um dos princípios elementares da arborização urbana. Sabemos que outros fatores como a adaptação ao solo interferem na capacidade adaptativa das espécies exóticas. Contudo, a avaliação climática aponta para as divergências apriorísticas e grosseiras no manejo da arborização.

\section{Procedimentos metodológicos}

Foi realizado um censo ou inventário $100 \%$, entre os meses de maio e julho de 2018, em 24 praças públicas do município de Salinas. Foram inventariadas todas as espécies arbóreas vivas que possuíam circunferência à altura do peito (CAP) maior ou igual a $10 \mathrm{~cm}$, conforme determina a Resolução Conjunta IEF/SEMAD № 1905 de $12 / 08 / 2013$. Com relação à classificação quanto à origem, considerou-se como nativas, as árvores originadas do Brasil, e exóticas as árvores oriundas de outro país. As espécies não identificadas em campo foram fotografadas, e tiveram seus materiais vegetativos coletados para realização de exsicatas, e posteriormente encaminhados para o Laboratório de Sistemática Vegetal do IFNMG Campus Salinas, e aqueles indivíduos que não foram identificados neste, seguiram para o Herbário Dendrológico da Universidade Federal dos Vales do Jequitinhonha e Mucuri - Campus Diamantina - UFVJM para posterior identificação. O mesmo possui o reconhecimento oficial junto à Rede Brasileira de Herbários (RBH), ligada à Sociedade Botânica do Brasil (SBB).

A partir do inventário, buscou-se as áreas de endemismo das espécies exóticas e o levantamento da tipologia climática em Köppen-Geiger. A tradicional classificação climática de Köppen-Geiger foi escolhida por ser muito conhecida e explorada e ser utilizada em âmbito internacional, o que facilita as comparações entre regiões de diferentes continentes. A partir deste levantamento, foi estabelecida a comparação com a tipologia climática de Salinas (MG), de modo a averiguar o paralelismo climático entre o município estudado e as áreas de endemismo das espécies exóticas.

\section{RESULTADOS E DISCUSSÃO}

Antes de apresentarmos os resultados da pesquisa, é importante ressaltar que as tipologias climáticas, sejam na classificação de Köppen-Geiger ou em quaisquer outras, são, na verdade, classes subjetivas que se limitam por intermédio de intervalos e padrões numéricos. Desta forma, a partir do princípio da proximidade geográfica, há de se considerar a possibilidade de influência de padrões regionais próximos à localidade analisada. Por esta razão, os dados climatológicos de Salinas (MG) apontam para uma encruzilhada envolvendo as tipologias Aw, As e BSh. A proximidade como o limiar destas três categorias faz com que distintos recortes históricos de 30 a 35 anos como geralmente é convencionado (AYOADE, 2003) possam fazer a classificação municipal flutuar entre estas tipologias.

Como a discussão ambiental sistemática é relativamente recente na sociedade, cidades centenárias como Salinas (MG) sofrem com a falta de planejamento pretérita. Por essa razão, temos como hipótese a possibilidade de uma parcela expressiva das espécies exóticas plantadas no município apresentarem grandes diferenças entre o seu clima de origem e o tipo climático que vigora em Salinas (MG). Caso se confirme nossa hipótese, este estudo serve como inspiração para a atuação do poder público nas novas áreas de expansão urbana da cidade, para que a arborização urbana se dê alicerçada nos fundamentos alardeados pelos especialistas da área.

Foram inventariadas as espécies de 24 praças da área urbana do município de Salinas (MG) (Tabela 1). As praças possuem diferentes tamanhos, formas e topografias. A Praça Moisés Ladeia foi a que registrou o maior número de indivíduos (96). Em cinco das praças da cidade não se pode contar mais do que uma dezena de indivíduos.

No conjunto das praças foram avaliados 567 indivíduos distribuídos em 48 variações, dentre gêneros e espécies (Tabela 2). Destes, nove indivíduos não foram identificados (1,59\%). Do total de indivíduos identificados, 
340 (60,93\%) são representantes de espécies nativas. Consideramos como exóticas as espécies que não são endêmicas de nenhuma região brasileira, tendo sua área de origem no exterior. Se faz necessário relativizar este conceito, visto que, apesar de se situar em grande medida na zona tropical, o território brasileiro exibe variações em suas tipologias climáticas que não podem ser ignoradas.

Tabela 1. Número de indivíduos por praça.

\begin{tabular}{|c|c|}
\hline Nome da Praça & Número de indivíduos \\
\hline Moisés Ladeia & 96 \\
\hline Passarela da Alegria & 52 \\
\hline Belvedere & 49 \\
\hline Padre Leo & 42 \\
\hline Biblioteca & 32 \\
\hline Praça da cadeia velha & 29 \\
\hline Doutor Morais & 28 \\
\hline São Geraldo & 27 \\
\hline Bonfim & 21 \\
\hline Ana Guedes & 21 \\
\hline Cândido Village & 19 \\
\hline Vila Canaã & 19 \\
\hline Lar Santa Clara & 18 \\
\hline Santa Clara & 17 \\
\hline Rottary & 17 \\
\hline JK & 16 \\
\hline Procópio Cardoso & 15 \\
\hline Nova Esperança & 14 \\
\hline Liberdade & 10 \\
\hline Santa Mônica & 9 \\
\hline Enéas Felício Batista & 7 \\
\hline João Cardoso Araújo & 5 \\
\hline Faustina Pessoa & 4 \\
\hline Guimarães Sarmento & 3 \\
\hline Total & 567 \\
\hline
\end{tabular}

Os indivíduos identificados como espécies exóticas somaram 200 (35,84\%) (Tabela 3), tendo a sua origem muito diversificada, assim como a sua tipologia climática na classificação de Köppen-Geiger.

Em termos gerais, a introdução de espécies exóticas mostrou-se coerente frente ao paralelismo climático. A espécie Callistemon citrunus G. Don ex Loud (Escova de Garrafa), o gênero Phoenix spp. (Cascuda) e a espécie Archontophoenix cunninghamiana $\mathrm{H}$. Wendl. \& Drude (Palmeira Imperial), por exemplo, correspondem as mais abundantes tipologias exóticas do estudo realizado, ambos apresentando como área endêmica o domínio climático do tipo Aw, coerente com o clima salinense.

Tabela 2. Espécies inventariadas nas praças de Salinas (MG) com mais de 10 ocorrências.

\begin{tabular}{|c|c|c|c|}
\hline $\begin{array}{l}\text { Nome } \\
\text { popular }\end{array}$ & Nome científico & Origem & Ocorrência \\
\hline Oiti & $\begin{array}{l}\text { Licania tomentosa } \\
\text { (Bent.) Fritsch }\end{array}$ & Nativa & 67 \\
\hline Ipê & $\begin{array}{l}\text { Handroanthus } \\
\text { spp. }\end{array}$ & Nativa & 66 \\
\hline $\begin{array}{c}\text { Palmeira } \\
\text { com acúleos }\end{array}$ & Syagrus spp. & Nativa & 45 \\
\hline Aroeira salsa & Schinus molle L. & Nativa & 42 \\
\hline Jerivá & $\begin{array}{c}\text { Syagrus } \\
\text { romanzoffiana } \\
\text { Cham. }\end{array}$ & Nativa & 33 \\
\hline $\begin{array}{l}\text { Escova de } \\
\text { garrafa }\end{array}$ & $\begin{array}{l}\text { Callistemon citrinus } \\
\text { G. Don ex Loud }\end{array}$ & Exótica & 27 \\
\hline Cascuda & Phoenix spp. & Exótica & 23 \\
\hline Sibipiruna & $\begin{array}{l}\text { Caesalpinia } \\
\text { pluviosa DC. }\end{array}$ & Nativa & 22 \\
\hline $\begin{array}{l}\text { Palmeira } \\
\text { Imperial }\end{array}$ & $\begin{array}{l}\text { Archontophoenix } \\
\text { cunninghamiana } \\
\text { H. Wendl. \& Drude }\end{array}$ & Exótica & 20 \\
\hline $\begin{array}{l}\text { Cacho de } \\
\text { Ouro }\end{array}$ & $\begin{array}{c}\text { Cassia leptophylla } \\
\text { Vogel }\end{array}$ & Nativa & 18 \\
\hline Nim Indiano & $\begin{array}{l}\text { Azadirachta } \\
\text { indica A. Juss }\end{array}$ & Exótica & 17 \\
\hline Mangueira & $\begin{array}{c}\text { Mangifera indica } \\
\text { L. }\end{array}$ & Exótica & 17 \\
\hline $\begin{array}{l}\text { Palmeira- } \\
\text { areca }\end{array}$ & $\begin{array}{c}\text { Dypsis lutescens } \\
\text { H. Wendl }\end{array}$ & Exótica & 16 \\
\hline Moringa & $\begin{array}{c}\text { Moringa oleífera } \\
\text { Lamarck }\end{array}$ & Exótica & 14 \\
\hline Bouganville & Bougainvillea spp. & Nativa & 14 \\
\hline Ipê-mirim & $\begin{array}{l}\text { Tecoma stans (L.) } \\
\text { Jussieu ex. Kunth }\end{array}$ & Exótica & 12 \\
\hline
\end{tabular}

Espécies endêmicas de áreas exclusivamente ligadas ao domínio de climas da classe " $C$ " (temperados) e " $D$ " (frios) mostraram-se pouco representativas. Duas exceções se destacam nestas duas classes. A primeira, Delonix regia Bojer ex Hook. Raf. (Flamboyant), conta com oito indivíduos nas praças salinenses. Apesar de pertencer a classe " $C$ ", sabe-se que se origina de Madagascar, de onde recebe influências tropicais (classe A) e de climas secos (classe B), já que estas tipologias convivem em diferenças espaciais pouco expressivas. A segunda exceção, Morus nigra L. (Amora-preta), conta com sete 
indivíduos presentes no inventário. Originária da Ásia Menor, é submetida em sua área endêmica à classe koppeniana "D" (climas frios).

Tabela 3. Espécies exóticas inventariadas nas praças de Salinas (MG) com mais de 10 ocorrências.

\begin{tabular}{|c|c|c|c|}
\hline Nome científico & Quant. & Local de origem & Clima \\
\hline $\begin{array}{l}\text { Callistemon citrinus } \\
\text { G. Don ex Loud }\end{array}$ & 27 & Austrália & Aw \\
\hline Phoenix spp. & 23 & $\begin{array}{c}\text { África, Europa e } \\
\text { Ásia }\end{array}$ & $\begin{array}{c}\text { BWh, BSb, } \\
\text { Aw e Af }\end{array}$ \\
\hline $\begin{array}{l}\text { Archontophoenix } \\
\text { cunninghamiana H. } \\
\text { Wendl. \& Drude }\end{array}$ & 20 & Austrália & Aw \\
\hline $\begin{array}{c}\text { Azadirachta indica A. } \\
\text { Juss }\end{array}$ & 17 & Índia e Birmânia & BSh \\
\hline Mangifera indica $\mathrm{L}$. & 17 & $\begin{array}{c}\text { Sul e Sudeste da } \\
\text { Ásia }\end{array}$ & Aw \\
\hline $\begin{array}{c}\text { Dypsis lutescens } \mathrm{H} \text {. } \\
\text { Wendl }\end{array}$ & 16 & Madagascar & BSh \\
\hline $\begin{array}{c}\text { Moringa oleifera } \\
\text { Lamarck }\end{array}$ & 14 & $\begin{array}{l}\text { Noroeste da } \\
\quad \text { índia }\end{array}$ & BSh \\
\hline $\begin{array}{l}\text { Tecoma stans (L.) } \\
\text { Jussieu ex. Kunth }\end{array}$ & 12 & $\begin{array}{c}\text { México e Sul dos } \\
\text { EUA }\end{array}$ & $\begin{array}{l}\text { BSh e } \\
\text { BSk }\end{array}$ \\
\hline
\end{tabular}

Há de se ressaltar que algumas espécies pertencentes ao mesmo domínio climático podem oferecer diferentes resultados em sua adaptação a tipos climáticos diferentes. A Delonix regia, por exemplo, é resistente a temperaturas muito baixas e, ainda assim, consegue prosperar em áreas caracterizadas por temperaturas elevadas. Este exemplo reforça o fato de que não é somente o clima que define a adaptação das espécies exóticas. Contudo, há de se considerar o mesmo como um componente relevante do processo adaptativo.

Consideramos que o inventário realizado nas praças de Salinas (MG) apresentou como resultado as espécies que prosperaram. Este estudo, por meio de sua investigação, não aponta o histórico de tentativas e erros na eventual implementação de espécies exóticas. Ao avaliar a arborização já consolidada nas praças, é plausível considerar que as espécies e gêneros inventariados correspondem justamente àqueles que, ainda que apresentem ausência de paralelismo climático entre a região endêmica e Salinas (MG), prosperaram, demonstrando sua capacidade adaptativa frente às condições ambientais encontradas.

Destacamos ainda que, a pluralidade paisagística brasileira coloca em xeque a dicotomia envolvendo as espécies nativas e exóticas. Se por um lado a definição de exotismo referiu-se ao fato de uma espécie ser originária do exterior, por outro, faz sentido considerar que as diferenças climáticas entre as regiões brasileiras podem ser mais expressivas do que aquelas que se apresentam entre Salinas (MG) e algumas regiões do exterior. Deste modo, a classificação "nativa" talvez mereça se referir a biomas específicos e não a países.

Apesar de diversos equívocos observados na arborização urbana da cidade de Salinas (MG), como o plantio de árvores que destroem calçadas, o conflito da copa com a fiação e escolhas que favorecem a proliferação de pragas urbanas, há de se considerar que as espécies das praças da cidade são, em geral, compatíveis com as condições climáticas observadas, salvo raras exceções. Contudo, tal situação pode expressar o resultado de um longo processo de tentativa e erro, sendo o atual arranjo das espécies um resultado aquém do que havia sido planejado no momento da implementação da arborização.

Faz-se necessário observar as espécies que prosperaram e analisar de que forma elas podem integrar planos de expansão da arborização das novas praças da cidade, ou, ainda, adensar espécies nas áreas subutilizadas das praças já existentes.

\section{CONCLUSÕES}

Diferentemente da hipótese levantada neste artigo, as espécies exóticas das praças de Salinas (MG) apresentamse coerentes com o paralelismo climático entre a região de endemismo e o município em questão. As espécies inventariadas neste trabalho apresentam-se como possibilidades para a expansão e o manejo da arborização da cidade. Por esta razão, o inventário da arborização das praças da cidade, por si só, já possui relevância. Recomendamos a realização de inventários de arborização urbana nas cidades próximas a Salinas (MG), e que com ela possuam paralelismo climático. A ampliação de pesquisas na região pode diversificar as opções para o planejamento da arborização urbana regional sustentada pelos princípios defendidos pelas ciências florestais.

\section{AGRADECIMENTOS}

À Fundação de Amparo à Pesquisa do Estado de Minas Gerais (FAPEMIG) pela concessão da bolsa de pesquisa ao segundo autor durante o ano de 2018, e ao Instituto Federal do Norte de Minas Gerais (IFNMG), Campus 
Salinas.

\section{REFERÊNCIAS}

AYOADE, J.O. Introdução à climatologia dos trópicos. 4.ed. Rio de Janeiro: Bertrand Brasil, 2003.

CECCHETTO, C.T. et al. Arborização urbana: Importância e benefício no planejamento ambiental das cidades. 160 Seminário Internacional de Educação no Mercosul, p.01-13, 2014.

CHAVES, B.E. et al. Avaliação qualiquantitativa da arborização da sede dos municípios de Beberibe e Cascavel, Ceará, Brasil. Ciência Florestal, v.29, n.1, p.403-416, 2019.

COSTA, L.B.S. et al. Floristic survey of ornamental plants used in Dom Delgado University City at the Universidade Federal do Maranhão, São Luís, Maranhão State, Brazil. Ornamental Horticulture, v.23, n.4, p.451-459, 2017.

GUILHERME, F.A.G. et al. Urban arborization in public pathways of four cities in east Mato Grosso do Sul (MS) Brazil. Ornamental Horticulture, v.24, n.2, p.174-181, 2018.

INSTITUTO BRASILEIRO DE GEOGRAFIA E ESTATÍSTICA - IBGE, Diretoria de Pesquisas, Coordenação de População e Indicadores Sociais, 2019. Disponível em: https://www.ibge.gov.br/cidades-e-estados/mg/salinas.html

INSTITUTO NACIONAL DE METEOROLOGIA - INMET, Banco de Dados Meteorológicos para Ensino e Pesquisa - BDMEP, 2018. Disponível em <http://www.inmet.gov.br/portal/index.php? $r=b d m e p / b d m e p>$ Acesso 28 de mar. de 2020.

MARTINI, A. et al. A influência das diferentes tipologias de floresta urbana no microclima do entorno imediato. Ciência Florestal, v.28, n.3, p.997-1007, 2018.

MENEZES, E.S. et al. Crescimento de mudas de Peltophorum dubium (Spreng.) Taub. sob interferência de plantas espontâneas e forrageiras. BIOFIX Scientific Journal, v.4, n.2, p.153-159, 2019.

PINHEIRO, C.R.; SOUZA, D.D. A importância da arborização nas cidades e sua influência no microclima. Revista Gestão \& Sustentabilidade Ambiental, v.6, n.1, p.67-82, 2017.

SÁ JUNIOR, A. et al. Application of the Köppen classification for climatic zoning in the state of Minas Gerais, Brazil. Theoretical Application Climatology, v.108, p.1-7, 2012.

SANTOS, C.Z.A. et al. Análise qualitativa da arborização urbana de 25 vias públicas da cidade de Aracaju-SE. Ciência Florestal, v.25, n.3, p.751-763, 2015.

SECRETARIA DO ESTADO DE MEIO AMBIENTE E DESENVOLVIMENTO SUSTENTÁVEL / INSTITUTO ESTADUAL DE FLORESTAS - SEMAD/IEF. Resolução conjunta SEMAD/IEF no 1905, de 12 de agosto de 2013. Dispõe sobre os processos de autorização para intervenção ambiental no âmbito do Estado de Minas Gerais e dar outras providências. Diário Oficial [do]
Estado Minas Gerais. Belo Horizonte, Minas Gerais, 2013. Diário do Executivo, p.37-40.

SILVA, E.M.F. et al. Um novo ecossistema: florestas urbanas construídas pelo Estado e pelos ativistas. Estudos Avançados, v.33, n.97, p.81-101, 2019.

SOUSA, F.Q. et al. Impacts of the invasion by Cryptostegia madagascariensis Bojer ex Decne. (Apocynaceae Juss.) in the remnant of caatinga in the town of Ibaretama, Ceará state, Brasil. Ciência Florestal, v.27 n.4, p.1243-1255, 2017.

SOUSA, R.R. et al. Diagnóstico da arborização do Campus de Patos - PB. BIOFIX Scientific Journal, v.4, n.1, p.43-51, 2019.

TOLEDO, L.O. et al. Análise multivariada de atributos pedológicos e fitossociológicos aplicada na caracterização de ambientes de cerrado no norte de Minas Gerais. Revista Árvore, v.33, n.5, p.957-968, 2009.

Recebido em 01-04-2020 Aceito em 23-04-2020 